\title{
Assessing Physician Barriers to Cardiac Rehabilitation Referral Rates in a Tertiary Teaching Centre
}

\author{
Andrew Duncan MD, MK Natarajan, JD Schwalm
}

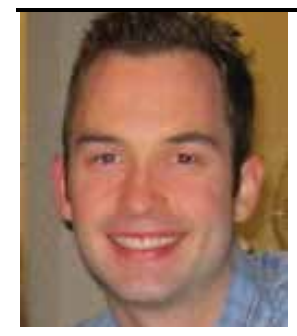

Duncan

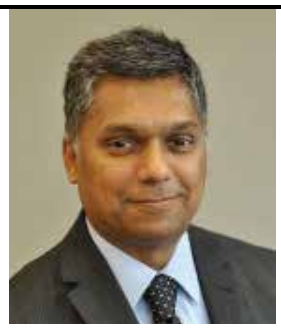

Natarajan

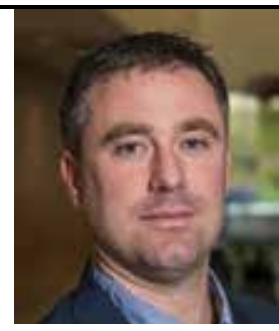

Schwalm

\begin{abstract}
About the Authors
Andrew Duncan is a General Internal Medicine Clinical Scholar at the University of McMaster who has a focal interest in Cardiac Rehabilitation as well as medical education. Dr. Duncan, $M K$ Natarajan MD and JD Schwalm MD are Interventional Cardiologists in the division of Cardiology, Department of Medicine and Investigators at the Population Health Research Institute, McMaster University, Hamilton, Ontario. Correspondence may be directed to andrew.duncan@medportal.ca.
\end{abstract}

\section{Abstract}

Introduction: Cardiac rehabilitation (CR) has a proven morbidity and mortality benefit, yet rates of referral remain low. We sought to elucidate the knowledge, utilization, referral, and endorsement practices of cardiac rehabilitation in a tertiary care centre.

Methods: A 13-question survey was electronically distributed to all Internal Medicine residents, Cardiology residents and subspecialty fellows, General Internal Medicine attendings and Cardiology attendings practising in a tertiary care centre. The survey assessed the physicians' knowledge of what CR entails, its benefits, patient eligibility and personal practices with respect to CR referral.

Results: The survey was distributed to 153 physicians with a response rate of nearly 60 percent. Compared to their medicine counterparts, Cardiology residents and staff had significantly improved knowledge with respect to what CR entails and eligibility criteria for referral (6.92 vs. 6.11 out of $9, p=0.036 ; 12.04$ vs. 10.76 out of $17, p=0.013$ ). Medicine residents and staff were less likely to be familiar with CR guidelines ( 72.02 vs. $32.69, \mathrm{p}<0.01$ ), and were less likely to discuss the importance of CR attendance with their patients ( 43.28 vs. $71.15, p=0.0002)$. A higher proportion of those in Medicine also reported being unsure of both how to refer eligible patients (59.12 vs. $13.46, p<0.0001)$ and which patients were eligible for CR (64.92 vs. 23.08, $p<0.0001)$. Higher knowledge scores and familiarity with CR guidelines was associated with higher self-reported referral rates.

Conclusion: This survey has identified clear physician barriers, most significant among internal medicine residents and staff. These barriers can help inform interventions to improve CR referral and enrolment rates.

\section{Résumé}

Introduction : La réadaptation cardiologique $(\mathrm{RC})$ a des effets bénéfiques avérés sur la morbidité et la mortalité, mais le taux de cas référés en la matière demeure faible. Nous avons donc cherché à clarifier quelques points relatifs à la réadaptation cardiologique dans un centre de soins tertiaires, à savoir : la connaissance de la réadaptation cardiologique, son utilisation, les habitudes d'aiguillage d'un patient vers cette technologie et les pratiques de recommandation.

Méthode: Un sondage comportant treize questions a été envoyé électroniquement à tous les résidents en médecine interne et en cardiologie, aux Associés et aux médecins traitants en cardiologie et en médecine interne pratiquant au sein d'un centre de soins tertiaires. Le sondage visait à évaluer le savoir en ce qui a trait à la réadaptation cardiologique et ses bienfaits, aux critères d'admissibilité d'un patient et aux pratiques relatives à l'aiguillage. 
Résultats : Le sondage a été acheminé à 153 médecins et a obtenu un taux de réponse de près de 60 pour 100. En comparaison de leurs collègues de médecine interne, les résidents, les spécialistes et les médecins traitants en cardiologie ont démontré avoir une connaissance significativement meilleure de la réadaptation cardiologique et des critères déterminant l'admissibilité et l'aiguillage d'un patient (6,92 vs 6,11 sur $9, p=0,036 ; 12,04$ vs 10,76 sur $17, p=0,013)$. Les résidents et les praticiens en médecine interne se sont révélés être moins au fait des lignes directrices relatives à la réadaptation cardiologique $(72,02$ vs $32,69, p<0,01)$, et moins portés à discuter de l'importance de l'assiduité des suivis nécessaires avec leurs patients (43,28 vs $71,15, p=0,0002)$. En médecine interne, une plus forte proportion de répondants ont rapporté ne pas être sûrs de savoir comment faire pour déterminer l'admissibilité d'un patient à la réadaptation cardiologique $(64,92$ vs $23,08, p<0,0001)$, puis pour aiguiller un patient admissible $(59,12$ vs $13,46, p<0,0001)$. Les résultats les plus élevés portant sur les connaissances de la réadaptation cardiologique et des lignes directrices afférentes se sont avérés être associés aux plus forts taux d'aiguillage rapportés.

Conclusion : Le sondage fait ressortir l'existence de difficultés au sein des médecins, plus particulièrement parmi les résidents et les praticiens en médecine interne. La connaissance de ces difficultés pourra contribuer à améliorer les interventions dans le but d'augmenter les taux de référence et d'adhésion relatifs à la réadaptation cardiologique.

\section{Introduction:}

Cardiac rehabilitation (CR) has been demonstrated to improve all-cause mortality by as much as $28 \%$ and reduce cardiac mortality by up to $31 \% .^{1-4}$ This has led to its inclusion in the Canadian Cardiovascular Society Guidelines for ischemic and non-ischemic cardiac disease. ${ }^{5}$ Despite this, CR rates of referral remain low..$^{6-9}$

In Canada, CR referral rates vary widely by province, with $18.6 \%$ of eligible patients being referred for CR in New Brunswick $^{7,8}$ and $36 \%$ in Ontario. ${ }^{8,9}$

CR programs are as cost effective as coronary artery bypass grafting $(\mathrm{CABG})$ or angioplasty for mortality reduction. ${ }^{10,11}$ Most CR programs carry a cost of less than $10,000 \$$ (USD) per Quality Adjusted Life Year (QALY). ${ }^{11}$

An "evidence practice-gap" exists with respect to $\mathrm{CR}$ referral. A gap is said to be present when there is a large disconnect between a known measure of practice quality and what is actually carried out. ${ }^{12-13}$ Reasons for a CR care gap may fall into three categories: the patient, the physician, and the health care system. ${ }^{13}$

There has been a substantial amount of research regarding patient and system barriers to participation in CR. ${ }^{14-20}$ Patients less likely to participate are those of low socio-economic status, those who lack transportation, older and noncaucasian patients, patients who are not married, those with co-morbidities or patients who lack awareness of program benefit. ${ }^{18-20}$ System issues include: increased wait-time between discharge and program commencement, timing of program scheduling (daytime vs. night-time) and the absence or presence of automatic referral systems. ${ }^{18-20}$

Recent data suggests that one of the strongest determinants of patient participation in CR is a strong endorsement from their physician. ${ }^{21}$ Additionally, referral rates can be enhanced when strong physician endorsement is combined with an automated referral. ${ }^{7}$ Lack of physician endorsement is a negative predictor of attendance to CR. ${ }^{19}$ Patients were twice as likely to attend cardiac rehabilitation when a strong endorsement was provided by a healthcare physician, compared to automatic referral alone. ${ }^{7}$

Taken together, physician-barriers to referral may be among the most important factors in patient participation, but paradoxically, these are the least researched. To improve physician endorsement and referral practices we must further determine the barriers to CR referral. To our knowledge, there has yet to be a study that has assessed physician barriers to referral in a tertiary care centre that includes not only staff, but also residents and fellows, who are often the front-line physicians in academic hospitals and are responsible for generating the initial referral.

\section{Methods:}

A survey tool was developed following an extensive review of the literature and discussion with key stakeholders, including practising residents, fellows, and staff physicians, to determine potential barriers to referral. A 13-question survey was developed that assessed both the physicians' knowledge of 
CR (Component 1) as well as their personal referral patterns (Component 2).

This survey was piloted on a sample of residents, fellows, and staff from other academic centres in Canada for readability and content. The survey was completed by physicians at various levels of training and included Internal Medicine residents $(n=50)$, Cardiology Fellows $(n=12)$, Cardiology Attendings $(n=14)$ and Clinical Teaching Unit (CTU) Staff $(n=15)$.

Following Research Ethics Board (REB) approval (HHS REB \# 12-139-C), the survey was electronically distributed to physicians operating in 2 tertiary care centres in the Hamilton Health Sciences (HHS) network. The survey question order was randomized for each participant by the host website.

\section{Component 1: Knowledge}

Knowledge of CR was divided in to 3 categories that included: knowledge of CR benefits, eligibility criteria, and what their local CR program entails.

The knowledge scores for each of the 3 areas comprised of a single question with multiple correct and incorrect answer possibilities. Each possible answer was equally weighted in the calculation of the overall knowledge score for each section. The overall aggregate score was the sum of correct answers selected minus incorrect selections. The total possible score varied for each knowledge section, depending on the number of possible answers. Total scores for knowledge of what CR entails, its benefits and CR eligibility were out of 9,12 and 17 respectively. A higher score indicated increased knowledge score of what CR entails.Correct answers were based on current Canadian Cardiovascular Society guidelines on CR referral. ${ }^{7}$

\section{Component 2: Referral Pattern}

Physician referral patterns and rates of referral were assessed with a combination of single answer questions using a 5 point Likert scales. The responses were converted to Normalized Units (NU) on a scale of $0-100$. When comparing cohorts, a difference of greater than 25 standardized units is considered statistically significant.

Average responses were calculated for each group of physicians for all three knowledge sections. Differences among the physicians at various levels of training were compared using a t-test or chi-square test. Analyses were not adjusted for multiple comparisons. Due to the survey collection method, only overall summaries were retained in the database for each question. As a result, the data were not linked across each variable during the survey collection to allow for covariate adjustment.

\section{Results:}

The survey was distributed to 153 physicians with a response rate of $59.4 \%(n=91)$. Compared to their medicine counterparts, Cardiology Residents and staff had a significantly higher self-reported rate of referral (Table 1). Seventy-five percent of Cardiology fellows reported referring greater than $50 \%$ of eligible patients, which was similar to the $64.5 \%$ of Cardiology staff. Comparatively, only $6 \%$ of IM residents and $0 \%$ of CTU staff reported referring greater than $50 \%$ of eligible patients. Cardiology fellows and staff reported referring significantly more eligible patients to cardiac rehabilitation compared to their medicine colleagues based on the difference in group proportions (Table 1).

Supporting Table 1: Self-Reported Rate of Referral

\begin{tabular}{|l|l|l|l|l|l|l|}
\hline & $\begin{array}{l}\text { IM Residents } \\
(\mathrm{n}=50)\end{array}$ & $\begin{array}{l}\text { Cardiology } \\
\text { Fellows } \\
(\mathrm{n}=12)\end{array}$ & $\begin{array}{l}\text { CTU } \\
\text { Attendings } \\
(\mathrm{n}=15)\end{array}$ & $\begin{array}{l}\text { Cardiology } \\
\text { Attendings } \\
(\mathrm{n}=14)\end{array}$ & $\begin{array}{l}\text { Difference } \\
\text { (delta) in Group } \\
\text { Proportions }\end{array}$ & $95 \% \mathrm{Cl}$ \\
\hline $\begin{array}{l}\text { Physlclans referrIng greater } \\
\text { than 50\% of ellglble patlents to } \\
\text { CR, } \mathbf{n} \text { (\%) } \\
\text { [Reference Flgure 1] }\end{array}$ & $3 / 50(6 \%)$ & $9 / 12(75 \%)$ & $0 / 15(0 \%)$ & $9 / 14(64.5 \%)$ & & \\
\hline $\begin{array}{l}\text { Differences: } \\
\text { [IM Residents]-[Cardiology } \\
\text { Fellows] }\end{array}$ & & & & & -0.69 & $-0.94,-0.44$ \\
\hline $\begin{array}{l}\text { [IM Residents]-[CTU } \\
\text { Attendings] }\end{array}$ & & & & & 0.060 & $-0.0058,0.13$ \\
\hline $\begin{array}{l}\text { [IM Residents]-[Cardiology } \\
\text { Attendings] }\end{array}$ & & & & & -0.58 & $-0.84,-0.32$ \\
\hline $\begin{array}{l}\text { [Cardiology FellowS]-[ CTU } \\
\text { Attendings] }\end{array}$ & & & & & 0.75 & $0.51,0.99$ \\
\hline $\begin{array}{l}\text { [Cardiology Fellows]-[ Cardiology } \\
\text { Attendings] }\end{array}$ & & & & & -0.64 & $-0.24,0.46$ \\
\hline $\begin{array}{l}\text { [CTU Attendings]-[Cardiology } \\
\text { Attendings] }\end{array}$ & & & & & $-0.89,-0.39$ \\
\hline
\end{tabular}

[a] Note: Delta was defined as the difference in self-reported rates of referral between groups. $95 \% \mathrm{Cl}$ for the difference in proportions. 
Supporting Table 2: Knowledge Scores

\begin{tabular}{|l|l|l|l|l|l|}
\hline $\begin{array}{l}\text { Knowledge Scores, } \\
\text { mean (SD) }\end{array}$ & $\begin{array}{l}\text { Medicine Residents and } \\
\text { CTU Attending } \\
\text { ( } \mathrm{n}=67 \text { ) }\end{array}$ & $\begin{array}{l}\text { Cardiology Residents } \\
\text { and Attendings } \\
\text { (n=26) }\end{array}$ & Mean Difference (delta) & $95 \% \mathrm{Cl}$ & $\mathrm{p}$-value \\
\hline $\begin{array}{l}\text { CR Program/What CR } \\
\text { entails[b] }\end{array}$ & $6.11(1.72)$ & $6.92(1.49)$ & -0.82 & $-1.58,-0.053$ & $\mathrm{p}=0.036$ \\
\hline $\begin{array}{l}\text { Patient are eligible for } \\
\text { referral[c] }\end{array}$ & $10.79(1.99)$ & $12.04(2.46)$ & -1.25 & $-2.23,-0.27$ & $\mathrm{p}=0.013$ \\
\hline CR benefits[d] & $5.36(2.22)$ & $6.23(2.07)$ & -0.87 & $-1.87,0.14$ & $\mathrm{p}=0.089$ \\
\hline
\end{tabular}

[a] Note: Delta was defined as the group mean difference between "Medicine Residents and CTU Attending" and "Cardiology Residents and Attendings". $95 \% \mathrm{Cl}$ for the difference in means.

[b] scale score range from 0 to 9 , higher score $=$ greater knowledge

[c] scale score range from 0 to 17 , higher score = greater knowledge

[d] scale score range from 0 to 12, higher score = greater knowledge

Supporting Table 3: Personal Practices and Self Reported Values

\begin{tabular}{|l|l|l|l|l|l|}
\hline $\begin{array}{l}\text { Personal practices } \\
\text { and self reported } \\
\text { values [a], mean (SD) }\end{array}$ & $\begin{array}{l}\text { Medicine } \\
\text { Residents and } \\
\text { CTU Attending } \\
(\mathrm{n}=67)\end{array}$ & $\begin{array}{l}\text { Cardiology } \\
\text { Residents and } \\
\text { Attendings } \\
(\mathrm{n}=26)\end{array}$ & $\begin{array}{l}\text { Mean Difference } \\
\text { (delta) }\end{array}$ & $95 \% \mathrm{Cl}$ & $\mathrm{p}$-value \\
\hline $\begin{array}{l}\text { Unfamiliar with CR } \\
\text { guidelines[b] }\end{array}$ & $72.02(26.30)$ & $32.69(25.27)$ & 39.32 & $27.38,51.27$ & $<01$ \\
\hline $\begin{array}{l}\text { Unsure of who to } \\
\text { refer[b] }\end{array}$ & $64.92(27.20)$ & $23.08(26.38)$ & 41.85 & $29.47,54.23$ & $<.0001$ \\
\hline $\begin{array}{l}\text { Unfamiliar with how } \\
\text { to refer eligible } \\
\text { patient[b] }\end{array}$ & $59.12(33.29)$ & $13.46(16.17)$ & 45.63 & $32.04,59.22$ & $<0001$ \\
\hline $\begin{array}{l}\text { Discuss the } \\
\text { Importance of CR } \\
\text { attendance[b] }\end{array}$ & $43.28(31.56)$ & $71.15(28.89)$ & -27.87 & $-42.03,-13.71$ & 0.0002 \\
\hline
\end{tabular}

[a] Note: Delta was defined as the group mean difference between "Medicine Residents and CTU Attending" and "Cardiology Residents and Attendings". $95 \% \mathrm{Cl}$ for the difference in means.

[b] measured in Normalized Units (NU), score ranges from 0 to 100, higher score = greater knowledge

Cardiology residents and staff had higher aggregate knowledge score of what CR entails, as well as of which patients are eligible for referral as compared to their medicine colleagues $(6.92 / 9$ vs. $6.11 / 9, p=0.036,12.04 / 17$ vs. $10.76 / 17$, $p=0.0013$, respectively) (Table 2 ). There was no significant difference between Cardiology residents and staff with Internal Medicine residents and staff with respect to CR benefits (6.23/12 vs. $5.31 / 12, p=0.089$ (Table 2 ).

When compared to their Cardiology counterparts, Medicine residents and staff were less likely to be familiar with CR guidelines (72.02 NU vs $32.69 \mathrm{NU}, p<0.01$ ), and were less likely to discuss the importance of $\mathrm{CR}$ attendance with their patients (43.28 NU vs. $71.15 \mathrm{NU}, p=0.0002$ ), a crucial component of patient compliance (table 3 ). Further, when asked why patients were not referred to $\mathrm{CR}$, medicine residents and staff reported they were unsure with both how to refer eligible patients (59.12 NU vs. $13.46 \mathrm{NU}, p<.0001)$ and which patients were eligible for referral to $\mathrm{CR}(59.12 \mathrm{NU}$ vs. 13.46 NU, $p<.0001$ ) (Table 3).

\section{Discussion:}

This survey highlights significant gaps in CR referral practice, particularly among the Internal Medicine specialty as compared to cardiology. Physicians who have either completed or who are undergoing Cardiology training had improved knowledge with respect to $\mathrm{CR}$ and had significantly higher self-reported rates of CR referral.

While it is difficult to identify the exact factors leading to higher self-reported referral patterns within the Cardiology specialty, it is likely a combination of greater understanding of CR benefits and eligibility criteria, as well as comfort with the referral process given the high volume of exposure to eligible patients. Further, Cardiology residents and staff are often directly involved with the CR program and are therefore likely to have increased familiarity with the program.

A recent internal audit at HHS showed that the Internal Medicine service admits and manages $87.5 \%$ of ACS patients. This may represent an opportunity for education within the Internal Medicine training program where CR eligible patients are frequently encountered, but infrequently referred to CR. Interestingly, both Cardiologists and the Medicine service utilize identical admission order sets with the automatic, "tickbox" for CR referral.

Educational programs targeting the above barriers to physician referral, including high-yield information concerning the benefits of CR, eligibility criteria, as well as clear instruction on the local referral process may help to narrow the gap in referral rates between these two practice areas. The 
importance of physician endorsement should be highlighted, as this has been shown to have the highest yield for patient adherence when combined with automated referrals.

Limitations of this study include a small sample size among Cardiology residents and staff as well as Internal Medicine staff. This is the result of program size limitations in a single academic centre. Other potential confounders include the inability to generalize results to non-responders. Multiple electronic mail reminders were sent to all groups to increase response rates in order to minimize this selection bias. Of note, it's possible that non-responders in Internal Medicine may be among the least informed group. Given this lack of inclusion, the discrepancy between the two groups may be understated as Cardiology residents had a $100 \%$ response rate compared to $57 \%$ of Internal Medicine residents. Finally, years of experience of staff and resident physicians may play a role in knowledge and clinical practice, however this study was not powered to investigate these differences.

As mentioned, there exist three barriers to CR referral, at the patient level, the physician level, and the health system level. This study has helped identify barriers at the physician level in a tertiary care centre involving trainees at various levels of training. Education for physicians targeting the above barriers may help increase referral to $\mathrm{CR}$, a resource known to improve mortality and morbidity.

\section{Conclusion:}

This survey has identified several important physician barriers to CR referral, particularly among physicians without formal Cardiology training. Future Knowledge Translation interventions should target educational initiatives that focus on increasing knowledge related to patient eligibility, simplification of the local referral process, and highlighting the importance of physician endorsement of CR programs. Such interventions coupled with an automated referral process may significantly increase participation of this beneficial and under-utilized resource.

Disclosures: J-D Schwalm holds a McMaster University, Department of Medicine, Internal Career Research Award. Acknowledgements: None

Funding: None

\section{References:}

1. Taylor RS, Brown A, Ebrahim S et al. Exercise-Based Rehabilitation for Patients with Coronary Heart disease: Systematic Review and Meta-analysis of Randomized Controlled Trials Am J Med. 2004;116:682- 692

2. Oldridge N, Guyatt G, Fischer M. Cardiac rehabilitation after myocardial infarction: combined experience of randomized clinical trials. JAMA. 1988;260:945-950.

3. Taylor R, Brown A, Ebrahim S, Jolliffe J, Noorani H, Rees K, Skidmore B, Stone J, Thompson D, Oldridge N. Exercise-based rehabilitation for patients with coronary heart disease: systematic review and meta-analysis of randomized controlled trials. Am J Med. 2004;116:682- 692.

4. Jolliffe J, Rees K, Taylor R, Thompson D, Oldridge N, Ebrahim S. Exercisebased rehabilitation for coronary heart disease (Cochrane review). Cochrane Database Syst Rev. 2001;(1):CD001800.

5. Mancini J, Gosselin G, Chow B, et al Canadian Cardiovascular Society Guidelines for the Diagnosis and Management of Stable Ischemic Heart disease Canadian Journal of Cardiology 30 (2014) 837-349

6 Lee A, Strickler G, Shepard D. The economics of cardiac rehabilitation:a review of literature. J CardiopulmRehabil. 2007;27:135-142.

7. Grace SL, et al. Systematizing Inpatient Referral to Cardiac Rehabilitation 2010: Canadian Association of Cardiac Rehabilitation and Canadian Cardiovascular Society Joint Position Paper Canadian Journal of Cardiology 27 (2011) 192-199

8. Cardiac Rehab New Brunswick. Annual Report to the NB Cardiac Services Advisory Committee.Saint John NB Heart Centre, 2008.

9. Candido E, Richards JA, Oh P, et al. The relationship between need and capacity for multidisciplinary cardiovascular risk-reduction programs in Ontario. Can J Cardiol 2011 200-207

10. Ades PA, Pashkow FJ, Nestor JR. Cost-effectiveness of cardiac rehabilitation after myocardial infarction. J CardiopulmRehabil 1997;17:222-31.

11. Brown AI, Garber AM. A concise review of the cost-effectiveness of coronary heart disease prevention. Med Clin North Am 2000;84:279-97.

12. Majumdar SR, McAlister FA, Furberg CD. From knowledge to practice in chronic cardiovascular disease: a long and winding road. J Am CollCardiol. 2004;43:1738-42. [PMID: 15145092

13. Grimshaw J, Eccles MP (2008). Knowledge Translation of Research Findings.In IHE Report June 2008: Effective Dissemination of Findings from Research. Institute of Health Economics, Alberta, Canada.

14. Sdringola S, Nakagawa K, Nakagawa Y, et al. Combined intense lifestyle and pharmacologic lipid treatment further reduce coronary events and myocardial perfusion abnormalities compared with usual-care cholesterollowering drugs in coronary artery disease. J Am CollCardiol 2003;41:263-72.

15. Belardinelli R, Paolini I, Cianci G, Piva R, Georgiou D, Purcaro A. Exercise training intervention after coronary angioplasty: The ETICA Trial. J Am CollCardiol 2001;37:1891-900.

16. Hambrecht R, Walther C, Mobius-Winkler S, et al. Percutaneous coronary angioplasty compared with exercise training patients with stable coronary artery disease: A randomized trial. Circulation 2004;109:1371-8.

17. HM Arthur, N Suskin, M Bayley, et al. The Canadian Heart Health Strategy and Action Plan: Cardiac rehabilitation as an exemplar of chronic disease management. Can J Cardiol 2010;26(1):37-41

18. Grace SL., Gravely-Witte S., Brual J et al. "Contribution of Patient and Physician Factors to Cardiac Rehabilitation Enrollment: A prospective Multi-Level Study"

19. Grace SL, Krepostman S., Brooks D., et al. "Referral to and discharge from cardiac rehabilitation: key informant views on continuity of care."

20. Jose A. Suaya, MD, Donald S. Shepard, Sharon-Lise T, et al. Use of Cardiac Rehabilitation by Medicare Beneficiaries After Myocardial Infarction or Coronary Bypass Surgery Circulation. 2007'116”1653-1662

21. Ades PA, Waldmann M, McCann W, Predictors of Cardiac Rehabilitation Participation in Older Coronary Patients. Arch Intern Med. 1992;152:10331035) 